\title{
Www.airqualitynow.eu, a common website and air quality indices to compare cities across Europe
}

\author{
S. vd. Elshout ${ }^{1}$, K. Leger ${ }^{2}$, H. Heich ${ }^{3}$, N. Hodges ${ }^{4} \&$ F. Nussio ${ }^{5}$ \\ ${ }^{I}$ DCMR, Rotterdam, Netherlands \\ ${ }^{2}$ Airparif, Paris, France \\ ${ }^{3}$ Heich Consult, Hürth, Germany \\ ${ }^{4}$ Leicester City Council, Leicester, UK \\ ${ }^{5}$ ATAC, Rome, Italy
}

\begin{abstract}
Air quality is a public concern. This is partly due to the "right to know" principle embodied in European legislation. Despite this common legislation, the way air quality is being interpreted and communicated differs considerably. For specialists raw monitoring data for Europe are available but these are not usable by the general public. Easy to understand and internationally comparable air quality information from one city to another is scarce. The CITEAIR project facilitates the comparison of urban air quality in near real-time by introducing two products: common air quality indices (hourly, daily and annual), implemented on a common website www.airqualitynow.eu. This paper describes these indices and presents their application on the common website. The indices and the website both aim at presenting the air quality of the participating cities in a comparable way. The website is designed to receive and display data from each city wanting to join. The main part is dedicated to compare the cities index values using different time scales (hourly, daily or annual) and for two types of exposure thanks to a background and a traffic index. In addition, space is offered to cities for presenting themselves according to a common template, providing background information on their specific air pollution situation and associated reduction measures. Participating is easy: cities upload their data through $\mathrm{ftp}$ and the indices calculations are automatically made. The website provides a dynamic picture of the air quality and is updated each hour enticing viewers to make repeated visits. However, participation with only a daily update or with yearly data is feasible as well. The indices and the website do not aim to replace more targeted local information. Their value added is to provide, for the first time, a European and comparable picture of the air quality in near real-time easily accessible through a common platform and presentation of the results.
\end{abstract}

Keywords: air quality index, public information, website, European platform. 


\section{Introduction}

The Framework directive and associated daughter directives on air quality in the European Union not only force member states to monitor and report on their air quality but also to actively inform the public on the status of the ambient air quality. The Aarhus convention, ratified by the EU in 2005, further enforces the concept that citizens have the right to be informed on the environmental conditions they live and work in. Over the past years a good number of cities and countries have started to display monitored or modelled air quality data on the internet. For most of the monitoring organisations, the internet is the easiest way to meet the dissemination of information requirements of the European (and/or national) legislation. The fact that so much air quality information is available on the internet makes it tempting to compare different cities in different countries. This proves particularly difficult. Apart from technical websites such as the European Environmental Agency's ozone website [1] and Airbase [2] there are no possibilities to compare cities/countries side by side. Even if one surfs from one site to the other, comparison is not easy: air quality is presented in different ways using different interpretation criteria and a different typology of stations, which is usually not clearly explained.

The most widespread way to interpret air quality on websites is the use of an index ranging from good to bad to make the detailed measurements in micrograms more understandable for the general public. A review of existing websites and the associated air quality indices shows that the way air quality is interpreted differs considerably across the world. More surprisingly, even amongst the EU member states who share common legislation, the indices used do vary. There are a number of reasons to explain these differences. Some of them are historical, others conceptual: the index existed before the EU regulations came into force or the index is based on health and exposure criteria, e.g. the UK index [3]. The fact that air quality problems (sources, meteorological conditions, etc.) tend to differ is also one of the reasons. The indices tend to be calibrated to the local situation, for example, to make sure that there is some variation in the index from day to day (to entice repeated visits) and that the typical range of pollutant conditions occurring locally is being covered.

To facilitate the international comparison of near real time air quality the CITEAIR project [4] (co-funded by INTERREG IIIC) has developed a common operational website www.airqualitynow.eu where cities can display their air quality information side by side. The project aims at making air quality comparable across Europe and www.airqualitynow.eu is already open for any city to join. The common website relies on common air quality indices (hourly, daily and annual). The comparison possibilities offered to the public are on an hourly, daily and yearly basis and the indices were developed keeping in mind that the general public is the end user. This paper presents the CITEAIR common website and its set of indices. It explains how they have been elaborated through collaboration between the partner cities (Leicester, Paris, Prague, Rome and Rotterdam) and is now open to any city willing to participate. 


\section{International comparison of cities air quality on the internet}

\subsection{Difficulties in comparing the European cities air quality}

CITEAIR provides a common index and makes a difference between background and traffic stations. The potential of having a common index on the same website will be apparent from the following example in which we try to compare air quality at a given day in four cities. The indices are described in Table 1. Three out of four cities have an index, two indices range from 1 to 10 , the other from 1 to 200 . Two cities have 10 classes, one has 5 , one has 4 . Two describe air quality in terms of good and bad, one in terms of health and the fourth in terms of pollution levels. The class boundaries are very different. In addition, whereas most websites have a page explaining how the index is calculated, other methodological aspects are generally not explained. Does the index represent measurements at background stations, traffic stations, a mixture?

Table 1: Indices used on the internet in Paris, Leicester, Rome and Rotterdam (situation in 2005)

\begin{tabular}{|c|ccc|c|cccc|c|}
\hline $\begin{array}{c}\text { ATMO } \\
\text { Paris }\end{array}$ & $\begin{array}{c}\text { ozone- } \\
1 \mathrm{~h}\end{array}$ & $\begin{array}{c}\text { PM10- } \\
24 \mathrm{~h}\end{array}$ & NO2-1h & index & UK & $\begin{array}{c}\text { ozone- } \\
8 \mathrm{~h}\end{array}$ & $\begin{array}{c}\text { PM10- } \\
24 \mathrm{~h}\end{array}$ & NO2-1h & index \\
\hline Very good & 29 & 9 & 29 & 1 & low & 32 & 21 & 95 & 1 \\
& 54 & 19 & 54 & 2 & & 66 & 42 & 190 & 2 \\
\hline good & 79 & 29 & 84 & 3 & & 99 & 64 & 286 & 3 \\
& 104 & 39 & 109 & 4 & moderate & 126 & 74 & 381 & 4 \\
\hline average & 129 & 49 & 134 & 5 & & 152 & 86 & 477 & 5 \\
\hline mediocre & 149 & 64 & 164 & 6 & & 179 & 96 & 572 & 6 \\
& 179 & 79 & 199 & 7 & high & 239 & 107 & 635 & 7 \\
\hline poor & 209 & 99 & 274 & 8 & & 299 & 118 & 700 & 8 \\
& 239 & 124 & 399 & 9 & & 359 & 129 & 763 & 9 \\
\hline Very poor & $>=240$ & $>=125$ & $>=400$ & 10 & very high & $>=360$ & $>=130$ & $>=764$ & 10 \\
\hline
\end{tabular}

\begin{tabular}{|c|ccc|c|cccc|c|}
\hline Rome & $\begin{array}{c}\text { ozone- } \\
\text { 1h }\end{array}$ & $\begin{array}{c}\text { PM10- } \\
\text { good }\end{array}$ & NO2-1h & index & Rotterdam* & ozone- & PM10- & NO2-1h & index \\
\hline goh & 100 & 100 & 50 & good & & 20 & 100 & - \\
\hline moderate & 135 & 150 & 150 & 75 & moderate & 180 & 40 & 200 & - \\
\hline mediocre & 180 & 200 & 200 & 100 & bad & 240 & 60 & 400 & - \\
\hline $\begin{array}{c}\text { unhealthy } \\
\text { very } \\
\text { unhealthy }\end{array}$ & 360 & 400 & 400 & 200 & very bad & $>240$ & $>60$ & $>400$ & - \\
\hline
\end{tabular}

* Ozone classification from the national smog pages, other classes from a local traffic website. 
If someone would like to compare these four cities at a given moment he or she would not only have to visit four websites but also be faced with four completely different presentations, qualifications and languages. Apart form the fact that the bands differ from one country/city/area to the other, the data behind the index also differ. This is hard for a specialist and almost impossible for the general public. The CITEAIR initiative comes from this situation.

\subsection{Comparing European cities thanks to a common website}

The CITEAIR common website www.airqualitynow.eu has been launched in March 2006. www.airqualitynow.eu is meant to be an interesting complement to the cities own websites. The website and the corresponding indices are not launched to replace existing websites or indices. Their value added is to provide for the first time a European and comparable picture of the air quality at first glance, up to date and understandable by anybody for:

- three time scales (on a hourly, daily and an annual basis),

- and two types of public exposure to air pollution (background and traffic conditions).

In addition, for those cities that are not yet on the internet, and/or do not currently use an index, "air quality now" and its indices could be their primary platform to easily provide information to the public and the local authorities. A space is also offered to cities for presenting themselves according to a common template, providing background information on their specific air pollution situation and associated reduction measures.

The website is operational with 16 cities feeding their data (see Figure 1). Some developments are still ongoing to improve its design and ergonomics and other cities are invited to join and upload their data as well. The process to join has been made easy. Based on the data sent by the cities through an agreed ftp format, the indices calculations are automatically done inside www.airqualitynow.eu. The full procedure is detailed on the "join us" page. However, not every city has its own monitoring network or both traffic and background stations, and not everyone is able to deliver data in near real time. If cities want to participate in only one of the indices, can only deliver data on a daily basis, or even only present year average data, they can still join the website. Different sections of the website provide a platform to compare different data (year average, daily, hourly). Participation is therefore not limited to those with their own automated monitoring network.

Www.airqualitynow.eu does not aim to replace more targeted existing local information. This would be an unrealistic ambition as in many cities the public has got used to the local, tailor-made index. The proposed common indices are, by the nature of the fact that they are common to a wide area, a non-specific compromise. CITEAIR envisages that there is room for two sources of air quality information on the internet: a local website, in the national language with a dedicated presentation (often using a well established and known local index); and a common website aimed at comparing - in near real time - the air quality in your own city to the air quality in other European cities. 

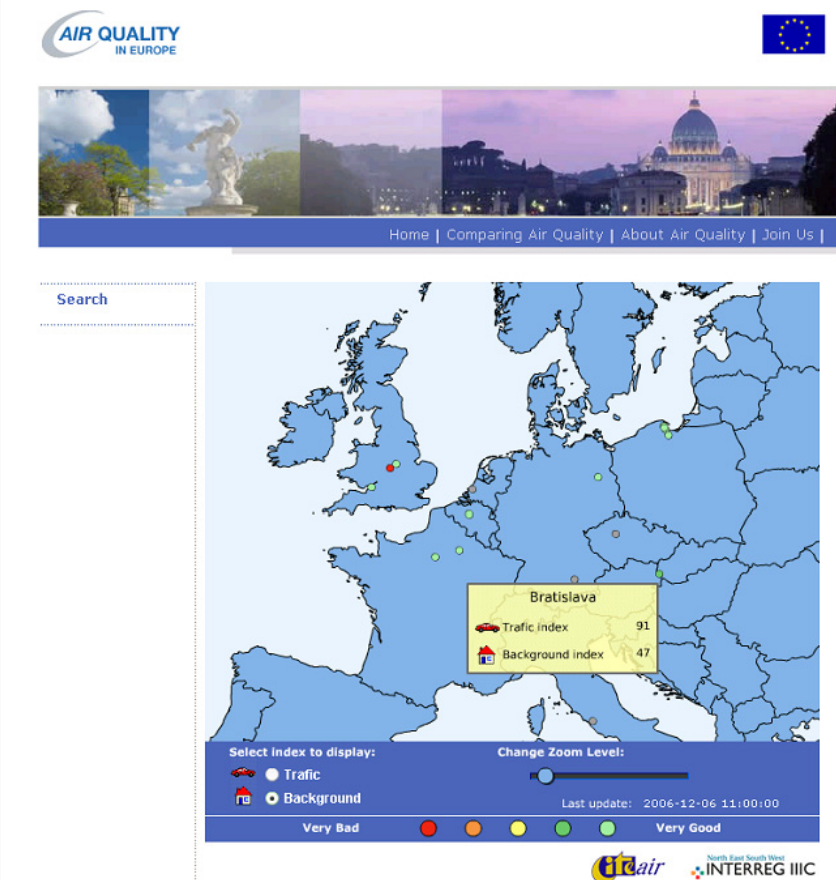

Ġair \%INTERREG IIIC

Q COPYRIGHT CITEAIR 2005

Figure 1: Home page of the CITEAIR common web site www.airqualitynow.eu presenting the comparison of air quality in European cities through common indices.

\section{International comparison of cities thanks to common air quality indices}

\subsection{Review of air quality indices}

There are a number of different ways to interpret air quality in near real time. The most common way to do so is the use of an index, generally based on a number of sub-indices for individual pollutants. Air quality indices aim to translate the chemical characteristics of a quite complex mixture of pollutants in the air into one single figure. From a scientific point of view this is obviously a gross generalisation but for communication purposes it is considered an essential simplification. An index is also always a compromise between several objectives and potentially occurring situations. The trade-offs in developing the common indices were made having in mind that they should be applicable over a wide range of conditions and interesting to the public.

There is a wealth of indices and countries that share the same legislation, or sometimes even areas/cities within the same country, have different 
indices $[5,6]$. Some of the differences can be explained by the local differences in the nature of the air quality problems. Some other differences are due to fundamentally different approaches. For example, the UK and US-EPA indices [7] are strongly related to perceivable health effects. The bands in the index are explained in health terms. This implies that the index covers a very wide range of concentrations and that the observed concentrations are very often in the "good" or "moderate" end of the scale. Air quality in Europe, fortunately, is rarely poor enough to cause acute health effects so any index based on health impacts tends to trail at the lower end of the scale for most of the time.

Other indices take a different approach. For example the ATMO index, based on a national regulation concerning all French cities larger than 100000 inhabitants [8] has bands that are somehow linked to values that are also used in the current EU directives. The alert thresholds in the directives tend to define the higher end of the scale. In these cases the top end of the index scale ends somewhere in the middle of the health effect based scales. For example the worst end (very poor) of the $\mathrm{NO}_{2}$-index in France corresponds to $400 \mu \mathrm{g} / \mathrm{m} 3$. In the UK this is in the lower end of the "moderate" band and in the US it is even considered too low to calculate an index value.

Communication-wise the health-based indices have both a clear advantage and a disadvantage. The advantage is that the index value displayed at the website is easy to interpret: it does or does not cause health effects. The disadvantage is that the index is almost always indicating that air quality is good and pollution is low whereas the limit values for long-term exposure are often exceeded. This leads to an apparent paradox: a citizen regularly checking the local air quality website will always get the message that the air quality is good whereas at the end of the year local government puts out a report that he or she is living in a hotspot area for which an action plan is required. This is the paradox between short- and long-term air quality criteria. The criteria for shortterm exposure are often met except for episodes, like for example in the summer of 2003. The criteria for long-term exposure are often not met in Europe's urban areas. The ATMO-type of indices provides some differentiation at the lower end of the scale to assure that the air quality is not always "good". However in this case it is very difficult to attach some kind of health interpretation to the index.

The long-term vs. short-term paradox typically occurs on the internet. In an annual report the focus is on long-term air pollution and in the teletext pages dedicated to smog warnings the focus and interpretation is based on short-term health effects. However, internet presentations often serve multiple roles: informing the public, but also making the public aware of air quality issues. In this case the paradox is difficult to resolve: highly variable hourly (or daily) data is being presented to assure an attractive and frequently changing presentation that encourages repeated visits. On the other hand, the most challenging limit values appear to be the criteria for the year average so interpreting commonly occurring hourly values in terms of good or bad is fairly arbitrarily. They are not bad from the short-term exposure point of view but might be bad from the long-term exposure point of view. This explains the need for an annual index as well. 


\subsection{A common daily and hourly index (CAQI)}

As already explained, comparing air quality in different cities is a tricky issue. Is the air quality being determined in the same way (this mainly applies to particulate matter) and at comparable locations? This is not an issue that the CITEAIR project and its indices can solve. Its common website will take for granted whatever a city supplies as input in either category. As a first step to improve comparability, the indices will be reported both for roadside and city background locations. This is considered an important improvement over city averages: some monitoring networks are designed to monitor or spot areas of poor air quality (with possibly a high number of roadside stations) whereas others are aimed at providing an average city picture.

The Common Air Quality Index (CAQI) is used both for a daily index and for an hourly index. In the website the daily index will be shown for the past day (D-1). For the current day, the hourly index will be available, to be updated every hour. A daily index for today would need forecasting or 'nowcasting' a facility that is not available in each city with a monitoring network, hence the option of an hourly index. The hourly index is also a reasonably dynamic parameter, enticing repeated visits to a website.

The CAQI is calculated according the grid in Table 2, by linear interpolation between the class borders. The final index is the highest value of the sub-indices for each component. As can be seen there are two CAQI-s: one for traffic monitoring sites and one for city background sites. The traffic index comprises $\mathrm{NO}_{2}$ and $\mathrm{PM}_{10}$, with $\mathrm{CO}$ as an auxiliary component. The background index obligatory comprises $\mathrm{NO}_{2}, \mathrm{PM}_{10}$ and $\mathrm{O}_{3}$, with $\mathrm{CO}$ and $\mathrm{SO}_{2}$ as auxiliary components. In most cities the auxiliary components will rarely determine the index (that is why they are auxiliary) but in a city with industrial pollution or a seaport $\mathrm{SO}_{2}$ might occasionally play a role. Benzene is considered a long-term exposure issue. The number of cities with online monitoring benzene is limited and it is therefore not included in the short-term indices.

The choice of the classes in the CAQI is inspired by the EU legislation and based on a compromise between the participating cities. The dividing line between medium and high is often linked mainly to the values mentioned in the directives: alert thresholds $\left(\mathrm{SO}_{2}, \mathrm{NO}_{2}, \mathrm{O}_{3}\right)$ or air quality objectives when available on a daily basis $\left(\mathrm{CO}\right.$ and $\left.\mathrm{PM}_{10}\right)$. Class borders were regularly spaced for the main components. PM10 is an exception. To avoid that the CAQI is completely dominated by $\mathrm{PM}_{10}$ the value of $50 \mu \mathrm{g} / \mathrm{m}^{3}$ as a daily average was positioned as the bordering line between low and medium. For the setting of the $\mathrm{CO}$ and $\mathrm{SO}_{2}$ borders additional inspiration was sought from the DAPPS index [9] which aims to define the component sub-indices based on the relative risks attributed to each component.

$\mathrm{PM}_{10}$ poses a particular problem. Many networks only report 24-hour (moving) average data. This different averaging time implies that their concentration readings are always lower than those for the networks reporting true hourly values. To resolve this inconsistency 24-hour averages are divided by 0.63 the average ratio between daily maximum hourly values and daily 
average values [6]. The $\mathrm{PM}_{10}$ grid is the hardest to find a suitable compromise and as the number of subscribers grows the suitability of the calculation grid will be reviewed.

Table 2: $\quad$ Pollutants and calculation grid for the CAQI.

\begin{tabular}{|c|c|c|c|c|c|c|c|c|c|}
\hline \multirow[t]{3}{*}{ Index } & \multirow[t]{3}{*}{ Class } & \multicolumn{3}{|c|}{ Traffic } & \multicolumn{5}{|c|}{ City Background } \\
\hline & & \multicolumn{2}{|c|}{$\begin{array}{l}\text { Mandatory } \\
\text { pollutant }\end{array}$} & \multirow{2}{*}{$\begin{array}{r}\begin{array}{r}\text { Auxiliary } \\
\text { pollutant }\end{array} \\
\mathrm{CO}\end{array}$} & \multicolumn{3}{|c|}{ Mandatory pollutant } & \multicolumn{2}{|c|}{$\begin{array}{l}\text { Auxiliary } \\
\text { pollutant }\end{array}$} \\
\hline & & $\mathrm{NO}_{2}$ & $\mathrm{PM}_{10}$ & & $\mathrm{NO}_{2}$ & $\mathrm{PM}_{10}$ & $\mathrm{O} 3$ & $\mathrm{CO}$ & $\mathrm{SO}_{2}$ \\
\hline \multirow[t]{2}{*}{ Very low } & 0 & 0 & 0 & 0 & 0 & 0 & 0 & 0 & 0 \\
\hline & 25 & 50 & 25 & 5000 & 50 & 25 & 60 & 5000 & 50 \\
\hline \multirow[t]{2}{*}{ Low } & 25 & 50 & 25 & 5000 & 50 & 25 & 60 & 5000 & 50 \\
\hline & 50 & 100 & 50 & 7500 & 100 & 50 & 120 & 7500 & 100 \\
\hline \multirow[t]{2}{*}{ Medium } & 50 & 100 & 50 & 7500 & 100 & 50 & 120 & 7500 & 100 \\
\hline & 75 & 200 & 75 & 10000 & 200 & 75 & 180 & 10000 & 300 \\
\hline \multirow[t]{2}{*}{ High } & 75 & 200 & 75 & 10000 & 200 & 75 & 180 & 10000 & 300 \\
\hline & 100 & 400 & 100 & 20000 & 400 & 100 & 240 & 20000 & 500 \\
\hline $\begin{array}{l}\text { Very } \\
\text { High* }\end{array}$ & $\begin{array}{c}> \\
100\end{array}$ & $\begin{array}{c}> \\
400\end{array}$ & $>100$ & $>20000$ & $>400$ & $>100$ & $>240$ & $>20000$ & $>500$ \\
\hline \multicolumn{10}{|c|}{$\begin{array}{l}\mathrm{NO}_{2}, \mathrm{O}_{3}, \mathrm{SO}_{2}: \\
\mathrm{CO} \\
\mathrm{PM}_{10}\end{array}$} \\
\hline
\end{tabular}

* An index value above 100 is not calculated but reported as " $>100$ "

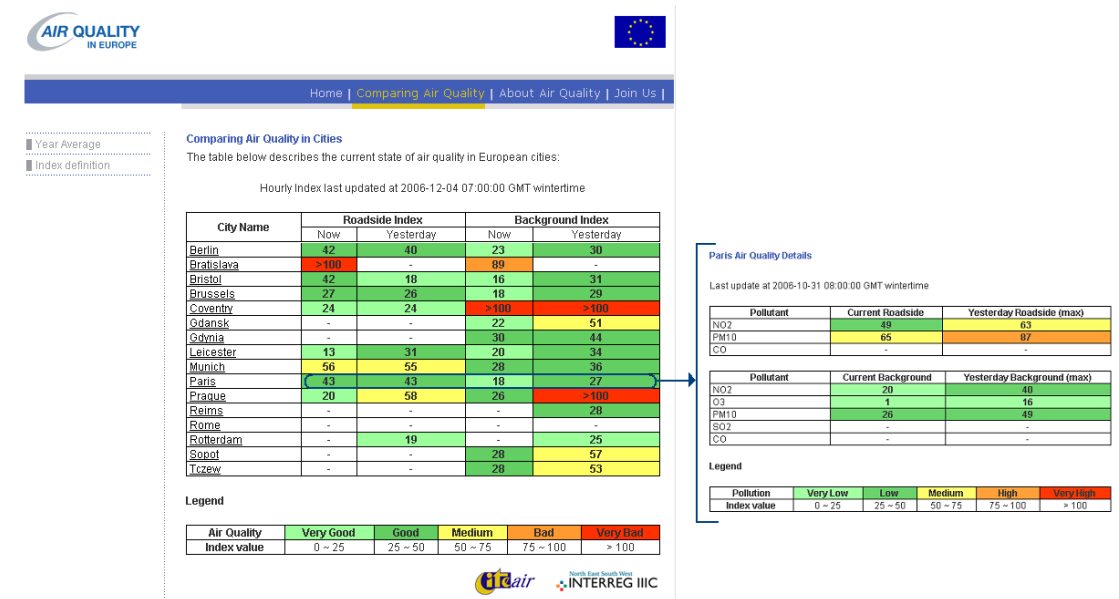

Figure 2: CAQI results for sixteen cities part of the CITEAIR project and details of the CAQI results for the agglomeration of Paris both displayed on www.airqualitynow.eu. 
The CAQI resembles the ATMO index discussed above and it differs substantially from for example the UK and US-EPA indices. It therefore shares the drawbacks of the ATMO (no clear link with health effects, fairly arbitrarily quality interpretation of hourly values). But it also shares its advantage: frequently changing index values that capture the hour-by-hour changes and make a website dynamic. The latter was of overriding importance as raising awareness is a key objective of the common website. de Leeuw and Mol [10] compared the CAQI to a number of other indices.

Figure 2 presents how the CAQI is displayed on www.airqualitynow.eu for the 16 current participating cities and the possible comparisons for a given day (e.g. the $4^{\text {th }}$ of December 2006) enabled by the index for two time scales and two types of exposure. As an example, the details of the CAQI calculation for Paris through its sub-indices are also provided.

\subsection{A common year average index (YACAQI)}

\subsubsection{Need for a year average index}

Year average indices are not very common in air quality reporting but they are nevertheless a useful indicator for non-experts, facilitating the comparison of cities at a glance. Comparing cities by their individual pollutant levels is difficult as one city might be better on one pollutant and worse on the other. In addition, some cities might monitor other pollutants than others. Even comparing progress in a single city from one year to the other is difficult as progress might be made for one pollutant whereas in another field things might have deteriorated. For example, was the progress on $\mathrm{NO}_{2}$ more important than the drawback on $\mathrm{PM}_{10}$ ? How to judge progress in such a case? A year average index is a huge simplification but it does provide an easy way to make some kind of relative assessment on the position of one city to the other or for one city from year to year.

A year average index can be devised according to a concentration grid in the same way as the traditional short-term indices discussed before. Akkan et al [11] propose such an index for Baden-Württemberg in Germany (Long-term Air Quality index - LAQx). This index uses long-term exposure (one year) health risks as a guiding principle for classifying air quality. Like the short-term exposure indices, the worst pollutant determines the index. Apart from its methodological merits, health (risks) being the main public concern, this is a very interesting approach.

Another way of making a (long-term) index is the "distance to target" principle. One advantage of the distance to target principle is that each parameter considered contributes to the index (unlike the principle where the worst parameter determines the index). A distance to target indicator calculates, for each pollutant, a ratio of how far the actual measurement is away from the target value, for example a limit value. The overall index/indicator is the average of the sub-indices. A distance to target index is based on policy targets or limit values. The limit and target values have important implications both for environmental policy makers and for the public. Besides, they do have a link to health risks: in Europe they are most of the time related to the recommendations of the World 
Health Organisation [12]. The distance to target the way of making an index is the year average index presented in this paper and used on www.airqualitynow.eu.

\subsubsection{Calculation and presentation of the YACAQI}

Like the hourly and daily index, the Year Average Common Air Quality Index (YACAQI) is calculated for traffic and city background sites. Preferably a city's data for each index is based on the average of a number of sites, however it is up to each city what they want to contribute and how they determine their contribution (monitored or modelled data). The www.airqualitynow.eu website will accept whatever a city submits as their city year average concentrations for each pollutant for traffic and city background situations (or for one of the indices if they do not want to supply both). In most cases, but this is up to individual cities, the data provided to the website will be based on the situation at one or more monitoring sites. This implies that it is not necessarily the complete and balanced picture a city reports under the EU-guidelines. Inferences on city compliance should therefore be based on the official city report and not on the index values on the website as they might not paint the full picture.

The calculation of the sub-indices is detailed in Table 3. Sub-indices are calculated for each pollutant by dividing the actual year average by the EU limit or target value. The overall city index is the average of the sub-indices for $\mathrm{NO}_{2}$, $\mathrm{PM}_{10}$ (both year average and daily averages) and ozone for the city background index. For the traffic year average index the averages of the sub-indices for $\mathrm{NO}_{2}$ and $\mathrm{PM}_{10}$ (both year average and daily averages) are being used. The other pollutants, if data are available, are used in the presentation of the YACAQI but do not enter the calculation of the city average index. They are treated as additional pollutants like in the hourly and daily indices. The main reason is that not every city is monitoring the full range of pollutants. Furthermore for $\mathrm{SO}_{2}$ we expect that the situation in different kinds of cities is very far apart, being no problem in most cities and a concern in others.

Table 3: Calculation basis for the year average index.

\begin{tabular}{|c|c|c|}
\hline Pollutant & Target value / limit value & Calculation \\
\hline $\mathrm{NO}_{2}$ & Year average is $40 \mu \mathrm{g} / \mathrm{m}^{3}$ & Year average / 40 \\
\hline $\mathrm{PM}_{10}$ & Year average is $40 \mu \mathrm{g} / \mathrm{m}^{3}$ & Year average / 40 \\
& Max. number of daily averages above 50 & Year average / 31 \\
& $\begin{array}{c}\mu \mathrm{g} / \mathrm{m}^{3} \\
35 \text { days } \approx \text { year average of } 31 \mu \mathrm{g} / \mathrm{m}^{3}\end{array}$ & \\
\hline Ozone & $\begin{array}{c}25 \text { days with an } 8 \text {-hour average value }>= \\
120 \mu \mathrm{g} / \mathrm{m}^{3}\end{array}$ & \# days with 8-hour average \\
& Year average is $20 \mu \mathrm{g} / \mathrm{m}^{3}$ & Year average / 20 \\
\hline $\mathrm{SO}_{2}$ & Year average is $5 \mu \mathrm{g} / \mathrm{m}^{3}$ & Year average / 5 \\
\hline Benzene & &
\end{tabular}

Figure 3 presents how the YACAQI is displayed on www.airqualitynow.eu for a selection of cities for two types of exposure, over a number of years. 
In addition, it provides the details of the YACAQI calculation for Paris through its associated background sub-indices. This type of presentation provides valuable additional information when comparing two cities or the same city over two years. At a glance it becomes evident what the main problems are and where progress for the situation is satisfactory.

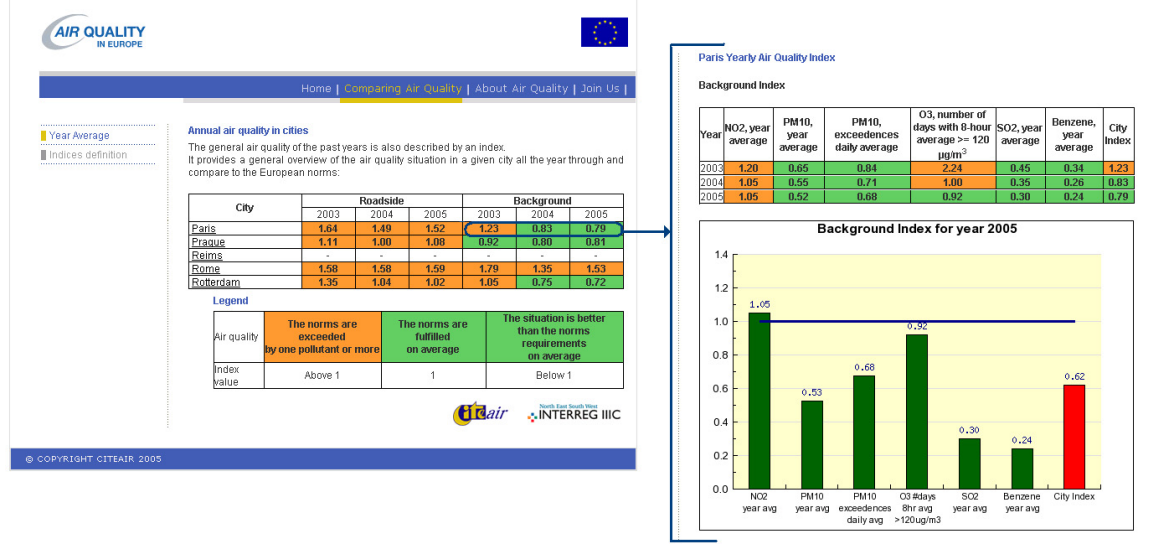

Figure 3: YACAQI results for four cities part of the CITEAIR project and details of the YACAQI results for the agglomeration of Paris (background conditions) both displayed on www.airqualitynow.eu.

Full details on the elaboration of CAQI and YACAQI, as well as sample application, are available in van den Elshout et al [6] and on www.airqualitynow.eu. Based on the experiences with their use the indices will be reviewed once at the end of the project, foreseen in 2007. So far $\mathrm{PM}_{10}$ appears to be the pollutant posing the greatest challenges in finding a compromise. A potential important change will also be the foreseen arrival of a $\mathrm{PM}_{2.5}$ limit value. Further developments of the CITEAIR project will take place in 2007: improvement of the common website, additional participating cities and an assessment of the indices after one year of functioning and peer review. Media will be contacted for a broader information display and a development of the CAQI forecast will be experienced.

\section{Conclusion}

Cities are engaged in communication with the public, not only because of legal obligations but also to raise awareness. This implies that air quality issues have to be presented in an attractive and educational way. The possibility to compare your own local air quality to a number of other European cities could be an asset in this respect. The purpose of common indices and website is not to replace more detailed local information nor to check EU regulation compliance but to complement it. The value added is to provide, for the first time, a European and 
comparable picture of the air quality, near real-time and understandable by anybody. In addition, the provision of separate indices for two types of environmental conditions and three time scales is a methodological innovation. It could also be an alternative to raise public awareness for cities which do not already operate a website.

\section{References}

[1] Ozone web, European Environmental Agency (EEA). http://ozone.eionet.eu.int

[2] AirBase, European Topic Centre on Air and Climate Change. http://airbase.eionet.eu.int

[3] Air Pollution Bandings and Index and the Impact on the health of People who are Sensitive to Air Pollution, Department for Environment, Food and Rural Affairs (DEFRA). www.airquality.co.uk/archive /standards.php\#band

[4] Common Information to European Air (CITEAIR). http://citeair.rec.org

[5] Garcia, J., Colossio, J. and Jamet, P. Air-quality indices. Elaboration, uses and international comparisons. Les presses de l'Ecole des Mines, Paris, 2002.

[6] Van den Elshout, Sef and Léger, Karine. Comparing Urban Air Quality Across Borders. A review of existing air quality indices and the proposal of a common alternative. Final draft 2006. http://citeair.rec.org /downloads/Products/ComparingUrbanAirQualityAcrossBorders.pdf

[7] Air quality Index: a guide to air quality an your Health, United States Environmental Protection Agency (USEPA). http://cfpub.epa.gov/airnow/index.cfm?action=aqibroch.index

[8] Indice ATMO, Agence de l'Environnement et de la Maîtrise de l'Energie (ADEME). www.buldair.org

[9] Cairncross, E. K. and John, J,. Dynamic Air Pollution Prediction System (DAPPS). Communicating air pollution exposure: a novel air pollution index system based on the relative risk of mortality associated with exposure to the common urban air pollutants. IUAPPA 13th Annual World Clean Air and Environmental Protection Congress and Exhibition. London, 2004.

[10] Leeuw, de Frank, and Mol, Wim.. Air quality and air quality indices: a world apart? ETC/ACC Technical paper 2005/5.

[11] Akkan, Z., Voss, J.-U., Kalberlah, F., Mayer, H. and Rost, J,. Luftqualitätsindex für langfristige Wirkungen (LAQx). Modellentwicklung and Anwendung für ausgewälte Orte in BadenWürttemberg. Landesanstalt für Umweltschutz Baden-Württemberg. Karlsruhe, 2004.

[12] Air quality guidelines for $\mathrm{PM}, \mathrm{O} 3, \mathrm{NO} 2$ and $\mathrm{SO}$ : summary of risk assessment, World Health Organisation (WHO), Global update 2005. http://www.who.int/phe/air/aqg2006execsum.pdf 